\title{
(Re)Ações da Associação Brasileira de Educação Musical em tempos de pandemia: entre adaptações e a construção de um novo futuro
}

\author{
Marcus Vinícius Medeiros Pereira \\ Universidade Federal de Juiz de Fora \\ Associação Brasileira de Educação Musical \\ markusmedeiros@yahoo.com.br \\ Mário André Wanderley Oliveira \\ Universidade Federal do Rio Grande do Norte/CAPES \\ Associação Brasileira de Educação Musical \\ mawoliveira@gmail.com
}

Resumo: A pandemia de COVID-19 é um fenômeno que, reconhecida como tal desde março de 2020, assola a humanidade, impactando, de diferentes modos e intensidades, países e regiões por onde circula o SARS-CoV-2. Tal fenômeno forçou a mobilização da totalidade dos setores da sociedade, redesenhando o cotidiano das instituições e das pessoas em todo o mundo. Em âmbito nacional, a Associação Brasileira de Educação Musical (ABEM), por meio de sua Diretoria (Gestão 2020-2021), tem lançado mão de estratégias diversas no intento de manter a área articulada e engajada, sobretudo em questões emergentes, por meio de ações online desde o início do período pandêmico. Neste texto, discorremos sobre tais empreendimentos, apresentando reflexões sobres mudanças na Associação - impulsionadas pela crise sanitária integrada às crises política, econômica e social pré-existentes no país, e intensificadas pelas políticas do atual governo — e, também, sobre o possível papel da Entidade no mundo pós-Covid-19.

Palavras-chave: ABEM, Pandemia de COVID-19, Enfrentamentos, Reações.

\section{(Re) Actions of the Brazilian Music Education Association in times of pandemic: between adaptations and the construction of a new future}

Abstract: The COVID-19 pandemic is a phenomenon that, recognized as such since March 2020, has plagued humanity, impacting, in different ways and intensities, countries and regions where SARS-CoV-2 circulates. This phenomenon forced the mobilization of all sectors of society, redrawing the daily lives of institutions and people around the world. At a national level, the Brazilian Association for Music Education (ABEM), through its Board (2020-2021), has used different strategies in an attempt to keep the area articulated and engaged, especially in emerging issues, through online actions since the beginning of the pandemic period. In this text, we discuss these undertakings, reflecting on changes in the Association driven by the health crisis integrated with the pre-existing political, economic and social crises in the country, and intensified by the policies of the current government - and also on the possible role of the Entity in the post-Covid-19 world.

Keywords: ABEM, COVID-19 Pandemic, Confrontations, Reactions.

\section{Notas introdutórias}

Discorrer sobre ações e reações de uma entidade acadêmico-científica frente a um fenômeno global, complexo, em curso e sobre o qual ainda não se pode afirmar, com 
precisão, que consequências a curto, médio e longo prazo deixará para a humanidade e para o planeta é uma tarefa difícil. A COVID-19 (sigla para Coronavirus Disease 2019), doença causada pelo Sars-Cov- $2^{1}$, foi reconhecida em seu estado pandêmico pela Organização Mundial da Saúde (OMS) em 11 de março de $2020^{2}$ (WHO, 2020) e teve, antes dessa data, o seu primeiro caso registrado no Brasil. De acordo com o Ministério da Saúde, o primeiro registro da doença no país ocorreu em 26 de fevereiro do mesmo ano (BRASIL, 2020). Ainda sem qualquer previsão para a sua erradicação, a pandemia encontra-se pujante, estando em distintos estágios e ondas nos mais diversos países do mundo, sem que, por ora, haja uma vacina que possa arrefecê-la.

Neste cenário, a pandemia tem, por um lado, como principais obstáculos, as chamadas medidas de "achatamento da curva de contágio" ${ }^{3}$, tais como o isolamento e o distanciamento social — recomendadas por pesquisadores/as da saúde pública e autoridades sanitárias de todo o mundo - , e, por outro, como fortes aliadas, (in)ações de governos adeptos ao negacionismo científico ${ }^{4}$ e com forte apoio popular. Convém mencionar que, em função da intensificação do negacionismo científico no período pandêmico, a OMS, em julho de 2020, reconheceu a infodemia ${ }^{5}$ - uma "pandemia de desinformação" - como um fenômeno a ser, com urgência, enfrentado de forma coordenada e sistemática, paralelamente ao combate à própria pandemia da COVID-19 (OPAS-OMS, 2020).

Com uma população estimada em 211,8 milhões de habitantes em 2020 (IBGE, 2020), o Brasil contabilizou e confirmou, em 24 de novembro deste ano, 6.118.708 casos de contaminação pela COVID-19 e 170.115 mortes dela decorrentes (BRASIL, 2020).

\footnotetext{
${ }^{1}$ Coronavírus da síndrome respiratória aguda grave 2 ou "novo coronavírus".

${ }^{2}$ É importante destacar que, embora reconhecida como pandemia em março de 2020, a doença já vinha se manifestando no mundo desde o final de 2019.

${ }^{3}$ Demonstração visual, em forma de gráfico, do que "as pessoas em geral podem fazer no sentido de contribuir para a atenuação da crise sanitária, independentemente do que, por um lado, as políticas de governo empreendidas e, pelo outro, as análises e recomendações da comunidade científica estejam postulando sobre o tema" (INFORMA SUS-UFSCAR, 2020).

${ }^{4}$ Fiorelli (2020) destaca que são exatamente os países com notória propagação de desinformação e com políticas sanitárias pouco claras que apresentam os maiores índices de contágio e morte pela COVID-19. ${ }^{5}$ Refere-se a "um grande aumento no volume de informações associadas a um assunto específico, que podem se multiplicar exponencialmente em pouco tempo devido a um evento específico, como a pandemia atual. Nessa situação, surgem rumores e desinformação, além da manipulação de informações com intenção duvidosa. Na era da informação, esse fenômeno é amplificado pelas redes sociais e se alastra mais rapidamente, como um vírus" (OPAS-OMS, 2020).
} 
Em todo o planeta, nesta mesma data, o número de casos registrados chegou a 59.658.035 e o de mortes, a 1.406.697 (JOHN HOPKINS UNIVERSITY, 2020).

A crise sanitária provocada pela COVID-19 tem sido, portanto, extraordinária e impactante em todo o mundo e, em países como o Brasil, se integra fortemente a crises pré-existentes - políticas, econômicas, sociais etc. - agravando-as significativamente. Não por acaso, estudiosos/as da saúde pública em todo o mundo, como Merrill Singer, antropólogo e médico estadunidense, Tiff-Annie Kenny, da Universidade Laval (Canadá), e Richard Horton, editor-chefe da Revista The Lancet, têm defendido que a COVID-19 seja considerada uma sindemia, em vez de uma pandemia (HORTON, 2020; CEE-FIOCRUZ, 2020). Essa mudança de perspectiva, no entendimento desses pesquisadores/as, tornaria cogente a análise das condições dos contextos sociais e ambientais que, por exemplo, tornam grupos da sociedade mais vulneráveis que outros à COVID-19. Esse entendimento parece ser compartilhado, em grande medida, por Santos, Pontes e Coimbra Jr. (2020), os quais consideram a COVID-19 - em escala global ou em cada um dos países em que está instalada - um "fato social total". Apoiando-se na acepção de Maurice Mauss, os autores propõem que a pandemia seja um fenômeno que põe em movimento a totalidade da sociedade e das suas instituições (SANTOS; PONTES; COIMBRA JR., 2020), o que nos força a repensar as formas de estarmos, como espécie, no mundo.

De acordo com a UNESCO (2020), a pandemia, desde o seu início, interrompeu as atividades presenciais de $91 \%$ dos/as estudantes em todo o mundo. E, como lembram Gusso e colaboradores/as (2020), diferente do que se projetava em abril de 2020, quando se cogitava que as medidas de controle da COVID-19 se estenderiam por dois ou três meses, as recomendações de distanciamento social, em novembro de 2020 , persistem sem que haja ainda previsão para o seu término no Brasil. Em todo o mundo, a preocupação de estudiosos/as, sobretudo em relação a países como o Brasil, é o acirramento de desigualdades sociais em função da pandemia ${ }^{6}$.

A pesquisa conduzida pela Fundação Carlos Chagas (FCC) com 14.285 professores/as de redes de ensino públicas e privadas de todas as 27 Unidades da Federação trouxe resultados que dão base à mencionada preocupação: 49,3\% das

\footnotetext{
${ }^{6}$ Cf. Furceri; Loungani; Ostry (2020).
} 
professoras acreditam que somente parte dos/as alunos/as consegue realizar as atividades propostas durante a pandemia; a expectativa dos/as professores/as em relação à aprendizagem dos/as estudantes diminuiu praticamente à metade; mais de $65 \%$ dos/as professores/as indicam que estão trabalhando mais do que antes (FCC, 2020).

É necessário considerar ainda, conforme a mais recente pesquisa do Comitê Gestor da Internet no Brasil (CGI, 2018), que 58\% dos domicílios no Brasil não têm computadores e 33\% não têm qualquer acesso à internet. Diante desse cenário, o prof. João Carlos Sales, presidente da Associação Nacional de Dirigentes das Instituições Federais de Ensino Superior (Andifes), frisa que, mesmo nas universidades, "[a] desigualdade é muito forte. Desigualdade de recursos, de condição para estudar, de tempo, dedicação" (SALLES, 2020).

Este é o contexto que antecede o ano em que a Associação Brasileira de Educação Musical (ABEM) completará os seus 30 anos de existência. Às vésperas desta celebração, a Entidade enfrenta, com o mundo, o maior desafio de sua história, ao mesmo tempo em que busca manter-se sólida, cumprindo suas funções como associação acadêmicocientífica. Com forte desinvestimento e ataques do governo federal - e, também, de diversos governos estaduais e municipais — nos últimos anos, a educação, a cultura ${ }^{7}$ e as ciências são setores severamente impactados pela pandemia no país. Dessa forma, pesquisadores/as, professores/as, estudantes e profissionais da educação e da cultura em geral têm sido impactados com a diminuição de recursos para a manutenção de suas atividades remotas e, em muitos casos, para manterem-se no cumprimento das medidas de isolamento e/ou distanciamento social.

\section{Funções das associações acadêmico-científicas e os papéis assumidos pela $\mathrm{ABEM}$ ao longo de sua história}

O papel das associações acadêmico-científicas pode parecer, à primeira vista, resumir-se à realização de congressos, encontros, fóruns e outras reuniões da comunidade que representa. A realização de tais eventos é, contudo, apenas uma

\footnotetext{
${ }^{7}$ A Lei n ${ }^{0}$ 14.017, de 29 de junho de 2020, que foi conhecida como Lei Aldir Blanc, traz o caráter de emergência em sua descrição, contudo, sua operacionalização não tem feito jus ao adjetivo. Artistas em geral e demais profissionais do setor, além de museus, teatros e casas de shows, apesar de terem sido os primeiros a paralisar suas atividades em função da pandemia, não haviam recebido nenhum auxílio financeiro sete meses após a suspensão de suas atividades.
} 
atribuição — que se articula a várias outras — dessas entidades. Compõe, comumente, o seu escopo uma série de funções, entre as quais se destacam: 1) o estímulo e o suporte à produção científica e à sua circulação; 2) a articulação com o poder público com vistas ao avanço de políticas públicas em seus setores; 3) o diálogo com instituições da área e suas redes na condução ou embasamento de seus processos e ações; 4) a promoção do diálogo entre pesquisadores/as da área com outras entidades da sociedade civil; e 5) o fortalecimento do senso de comunidade do grupo que representa.

Witter (2007, p. 2) esclarece que as sociedades científicas surgiram, em parte, como uma resposta à necessidade de institucionalização de comunidades de cientistas com interesses em comum. Isso porque o estreitamento de laços entre tais estudiosos/as potencializa as possibilidades de compartilhamento, avaliação, qualificação e reconhecimento mútuo dos seus trabalhos. Rodrigues (2008) menciona que, desde a fundação da primeira sociedade para o avanço da ciência, no século XIX, diversas instituições do tipo foram criadas no mundo, com vistas a promover o diálogo não apenas entre cientistas, mas entre a comunidade científica e setores diversos da sociedade. Tais articulações têm possibilitado, desde então, a construção de soluções conjuntas para problemas públicos. Oliveira (2017) frisa que essa função social das associações está presente mesmo em entidades científicas embrionárias, no século XVII ${ }^{8}$.

Assim, fomentar a criação e o fortalecimento de laços — e, em instância, de redes - entre estudiosos/as sempre foi um dos importantes papéis desempenhados pelas associações científicas. Sarah Gibson (1982, p. 149) defende que há, em cada uma dessas entidades, "um 'instinto comunal' para partilhar informação com os membros [das sociedades] e tornar as descobertas científicas genericamente disponíveis para outros grupos interessados" (GIBSON, 1982, p. 149). Todavia, mais do que tal disposição para estabelecer laços e partilhar "achados", é importante que os membros de uma associação estejam engajados nas causas mais gerais das associações de que fazem parte. Como afirma Madalena Oliveira:

[...] apesar da relevância reconhecida pelos cientistas em geral ao facto de se pertencer a uma associação, o grau de comprometimento dos associados é, não raras vezes, pouco expressivo; faltará aos membros das associações o sentido de militância e de envolvimento político que caracteriza outras

\footnotetext{
${ }^{8}$ Isso acontecia, por exemplo, quando "mercadores, filósofos, aristocratas e proprietários de terras (landed gentlemen) se reuniam para jantar antes das reuniões ou para tomar café depois das sessões para fazer network e socializar com os cientistas" (SIEGELMAN, 1998, p. 12 apud OLIVEIRA, 2017, p. 232).
} 
organizações coletivas como os partidos políticos ou os sindicatos (OLIVEIRA, 2014, p. 244).

Dentro deste espírito, a ABEM, entidade nacional sem fins lucrativos, com sede física em Londrina/ $\mathrm{PR}^{9}$, vem, desde 1991, atuando ativamente com o intuito de 1) congregar profissionais, professores/as e estudantes da Educação Musical e de áreas afins; 2) promover, organizar, sistematizar e consolidar o pensamento crítico e a pesquisa na área; 3) apoiar a formação e a atuação na área da Educação Musical ${ }^{10}$, contemplando diferentes níveis e modalidades da educação brasileira, além de contextos socioculturais e socioeducacionais diversos; e 4) fomentar e fortalecer o senso de comunidade da área na Educação Musical brasileira.

Frente a esses objetivos, a ABEM, ao longo dos seus 29 anos de existência, já promoveu, em diferentes cidades do país, 24 Congressos Nacionais ${ }^{11}$, além de 74 encontros regionais ${ }^{12}$. Tais congressos e encontros da Associação, com variações pontuais, sempre apresentaram uma configuração similar, contando com conferências, mesas-redondas, apresentações musicais, minicursos, sessões de lançamentos de livros, bem como sessões de comunicações, pôsteres e, mais recentemente, simpósios.

A partir de 2013, na gestão do professor Dr. Luis Ricardo Silva Queiroz, a ABEM passou também a realizar fóruns temáticos. Inicialmente, foram criados os fóruns dedicados à Pesquisa em Educação Musical, ao Ensino de Música nas Escolas de Educação Básica e à Formação de Professores de Música. Posteriormente, foi criado o Fórum de Ensino de Instrumentos Musicais e Escolas Especializadas de Música. Com encontros presenciais realizados anualmente e com formato compacto, os fóruns, desde

\footnotetext{
${ }^{9}$ A sede física da ABEM se localiza em Londrina/PR desde 2014. Anteriormente, as residências dos/as presidentes eram consideradas as sedes provisórias da Associação.

${ }^{10}$ Conforme consta no site da Associação (http://abemeducacaomusical.com.br/), o objetivo principal da Entidade é "promover a educação musical no Brasil, contribuindo para que o ensino da música esteja presente de forma sistemática e com qualidade nos diversos sistemas educacionais brasileiros, contemplando, de maneira especial, a educação básica; por essa razão tem estado atenta às múltiplas formas de desenvolvimento do ensino e aprendizagem da música no país, o que inclui a formação do educador musical e a observação dos processos de concurso público e de contratação de profissionais para o exercício da docência em música, nos diferenciados níveis escolares".

${ }^{11}$ Até 2011, o Congresso Nacional da ABEM acontecia anualmente. A partir desse ano, passou a ser realizado a cada dois anos, não acontecendo nos anos de realização dos encontros regionais.

${ }^{12}$ Dos 74 Encontros Regionais da ABEM, 19 foram realizados na região Sul; 16 na região Centro-Oeste; 15 na região Nordeste; 13 na região Sudeste; e 11 na região Norte. As edições de 2020 dos cinco Encontros Regionais da ABEM aconteceram de forma unificada $100 \%$ on-line.
} 
sua criação, têm permitido que o debate entre pessoas engajadas em campos temáticos específicos da área aconteça continuamente.

Como forma de fomentar e contribuir continuamente para a consolidação da literatura acadêmico-científica da área no país, são publicadas pela Associação, regularmente, novos números/volumes da Revista da ABEM (atualmente, com 43 números / 28 volumes) e da Revista Música na Educação Básica-MEB (com 09 números / 11 volumes). A Associação conta também com contribuições mais antigas, entre as quais vale mencionar a série Fundamentos da Educação Musical, com quatro volumes, e a Série Teses, com dois volumes. Cabe destacar, ainda, que, dos congressos nacionais e encontros regionais da ABEM, resultaram 98 anais de eventos, cuja maioria encontra-se disponível no site da Associação — assim como os demais materiais anteriormente citados. $\mathrm{O}$ crescimento e a expansão tanto qualitativa quanto quantitativa da pesquisa e da pós-graduação na área, ao longo dos anos de existência da ABEM, evidencia o importante papel da Associação no avanço da produção científica da Educação Musical e na qualificação da formação em pesquisa e da formação docente em música no país.

Atualmente, a ABEM é composta por órgãos deliberativos e administrativos: Assembleia Geral, órgão máximo da Associação, constituída pelos/as associados/as em sua totalidade; Diretoria, com mandato de dois anos, com direito a uma recondução, composta pela Presidência, pela Tesouraria e pela Secretaria; Conselho Editorial; Conselho Fiscal; Coordenação Regional; e Representações Estaduais. Não há remuneração para o exercício de qualquer uma dessas funções. A ABEM é vinculada à Associação Nacional de Pesquisa e Pós-Graduação em Música (ANPPOM), à International Society for Music Education (ISME) e, mais recentemente, à Sociedade Brasileira para o Progresso da Ciência (SBPC).

O número de os/as associados/as à ABEM, atualmente, gira em torno de $2.500^{13}$ pessoas. Entre os/as associados/as, encontram-se estudantes e professores/as de graduação e pós-graduação em música e área afins; professores/as de música de escolas de educação básica; professores/as e estudantes de escolas especializadas de música; professores/as de projetos sociais; professores/as de música em igrejas; regentes de coros, orquestras e bandas; além de profissionais da música e demais interessados/as na área de

\footnotetext{
${ }^{13}$ Considerando adimplentes e inadimplentes.
} 
Educação Musical. A comunidade que acompanha a ABEM e participa, em maior ou menor grau, de suas atividades, contudo, pode ser muito maior, tendo em vista que as mídias sociais da Associação contam, atualmente, com $13.566^{14}$ seguidores/as (somadas possíveis repetições) e os vídeos do seu canal no Youtube, especificamente, já foram visualizados, em seu conjunto, 32.743 vezes.

\section{A ABEM no período pré-pandemia (2018-2019)}

Sempre atenta ao contexto sociopolítico em que se situa, a diretoria da ABEM propôs, para o biênio 2018-2019, o seguinte tema orientador dos debates para seus eventos no período: "Educação Musical em tempos de crise: percepções, impactos e enfrentamentos". Àquela altura, o Brasil já atravessava um período de turbulências políticas, econômicas e sociais, quando o governo de Michel Temer ${ }^{15}$ implementava uma série de reformas ${ }^{16}$ incongruentes com o programa de governo aprovado pela maioria da população nas eleições de 2014. O tema para o biênio 2018-2019, buscou, assim, provocar a área a produzir reflexões sobre aquele momento e a propor estratégias para enfrentamentos naquele período de crise.

Com a eleição de Jair Bolsonaro para presidente do país no final de 2018, não seria incoerente a manutenção do tema do biênio 2018-2019 no biênio 2020-2021. Com o novo governo federal, certamente, as crises políticas, econômicas e sociais se intensificaram no Brasil, impactando, de modo ainda mais severo do que no período anterior, a educação, as ciências, a cultura, as artes, o meio ambiente e demais setores no país. Considerando, todavia, a demanda por proposições frente a essas crises diversas e, também, aos 30 anos da Entidade em 2021, o tema escolhido, no início de 2020, para o biênio 2020-2021 foi “A Educação Musical Brasileira e a construção de um outro mundo: proposições e ações a partir dos 30 anos de lutas, conquistas e problematizações da ABEM".

\footnotetext{
${ }^{14}$ Número de seguidores/as no Perfil da ABEM no Facebook: 4.996; número de seguidores/as na Página da ABEM no Facebook: 3.066; número de inscritos/as no Youtube: 2.550; número de seguidores/as do perfil do Instagram: 3.066 (contagens realizadas no dia 23 de novembro de 2020).

${ }^{15}$ Por muitos considerado como ilegítimo, após o impeachment da presidenta Dilma Rousseff em 2016.

${ }^{16}$ Reformas como a do Ensino Médio - realizada inicialmente por Medida Provisória -, a versão final (não dialogada) da Base Nacional Comum Curricular, a nova política nacional de formação de professores - que veio a se consolidar com a aprovação de uma Base Nacional Comum, em 2019 -, a reforma trabalhista que ocasionou uma grave perda de direitos historicamente conquistados, além da desprofissionalização do professor, a censura no campo das artes e as severas (e a partir de então crescentes) restrições orçamentárias no fomento à pesquisa.
} 
Pouco tempo depois, antes que qualquer iniciativa da ABEM se materializasse efetivamente em 2020, a pandemia da Covid-19 foi reconhecida pela OMS. A partir de março de 2020, medidas de isolamento e distanciamento social foram impostas à população em todo o mundo:

\begin{abstract}
A Organização Pan-Americana de Saúde (OPAS) indicou em seu sítio "web", que ainda na ausência de vacinas e tratamentos específicos que sejam seguros e eficazes, a implementação de medidas de distanciamento social visam minimizar a exposição a indivíduos infectados pelo vírus SARS-COV-2, reduzindo assim o número de casos e óbitos; evitando a sobrecarga dos serviços de saúde e achatando a curva epidêmica até que estejam disponíveis as medidas farmacológicas específicas (JESUS et al., 2020, p. 4).
\end{abstract}

\title{
A ABEM na pandemia (2020)
}

É fato que, antes da pandemia, a ABEM já ensaiava realizar eventos e ações totalmente on-line. A comunidade virtual em torno da Associação já vinha crescendo desde $2018^{17}$, quando as conferências e mesas-redondas de todos os eventos da Entidade passaram a ser, sistematicamente, transmitidos pela "ABEM nas Redes" no Facebook. A despeito da qualidade técnica das primeiras transmissões, muitas vezes realizadas por meio de smartphones, essa iniciativa permitiu que os eventos da ABEM começassem acontecer de forma híbrida. Isso porque o público, não apenas presente nos eventos, já podia participar, de suas casas, dos congressos, encontros e fóruns promovidos pela Associação. A realização de um evento $100 \%$ on-line já era, nesse período, uma possibilidade.

Com o advento da pandemia, os perfis, páginas e canais da ABEM nas principais plataformas on-line (Facebook, Twitter, Instagram, Youtube) - que, em sua maioria, já eram conhecidos por associados/as e seguidores/as da Associação — passaram a ser não apenas uma possibilidade para quem não podia estar nos eventos, mas a única

\footnotetext{
${ }^{17}$ Cabe destacar que, desde 2018, a ABEM tem buscado fortalecer a sua presença nas redes sociais. A modernização do setor de divulgação e comunicação da Associação foi uma das propostas das Diretorias eleitas em 2017 e em 2019 para as gestões nos biênios 2018-2019 e 2020-2021 respectivamente. A proposta inicial foi dar visibilidade às ações da associação não somente entre associados/as, mas para o público em geral. O propósito dessa modernização foi possibilitar 1) a divulgação de informes da Entidade, como documentos elaborados pela diretoria com comentários e análises de questões pertinentes à área; 2) a realização de coleta de informações para subsidiar ações da Associação; 3) a divulgação de notícias diretamente relacionadas à educação musical e, de forma mais abrangente, a políticas públicas em educação, ciências e cultura. Tais objetivos foram ampliados no decorrer dos últimos.
} 
possibilidade para todos/as que quisessem acompanhá-los e participar de suas atividades. Passaram, portanto, a ser ferramentas fundamentais da ABEM.

Neste período, como comenta Cláudia Werneck, fomos obrigados/as a nos reinventar em nossas casas:

Até a virtualidade se ressentiu - suas estruturas estão sobrecarregadas de tanta atenção. Quanto à humanidade, tornou-se duplamente refém: da Covid-19 e da virtualização. Antes, éramos seres humanos presenciais com a opção do online. Agora somos seres online com o risco do presencial (WERNECK, 2020, s. p.).

Embora já existissem em curso inúmeras pesquisas abordando a mediação das tecnologias nas práticas musicais e de ensino de música, tais práticas eram ainda pouco familiares para grande parte da nossa comunidade. Quantos/as imaginariam a necessidade de recorrer aos estudos sobre o ensino de música a distância, mediados pelas novas tecnologias? Quantos grupos musicais se viriam diante da necessidade - muitas vezes emocional - de fazer música apenas remotamente, com o auxílio de edições de vídeo, gravações, mixagens - totalmente online?

Ricardo Capra, em reportagem recente, afirmou que

(...) o futuro do trabalho chegou de um dia para o outro, fazendo com que as pessoas precisassem sair dos escritórios [e podemos acrescentar: do conforto de seus estúdios, teatros, salas de ensaio e de aulas] sem nenhuma expectativa de quando vão voltar, assumindo suas próprias casas como extensão das empresas. [...] Ninguém foi preparado para isso, ainda que a infraestrutura para a transformação digital estivesse à disposição - mas não em uso - e agora é preciso criar novos hábitos para atuar remotamente (CAPRA, 2020, s.p.).

Esse "futuro" afetou profundamente a estrutura tradicional dos eventos promovidos pela ABEM, sempre marcados pelas intensas trocas presenciais em seus encontros regionais, congresso nacional e fóruns temáticos.

\section{Experiências on-line nos fóruns da ABEM}

Diante do cenário da pandemia, e da indefinição da situação sanitária no país - e seus impactos sociais, econômicos, emocionais, entre tantos outros - a ABEM promoveu a realização de Fóruns (virtuais) de "Temas Emergentes da Educação Musical Brasileira" - buscando debater e ouvir a comunidade de educadores/as musicais sobre a situação. 
Essa foi a primeira experiência da Associação na organização de eventos inteiramente on-line.

$\mathrm{O}$ isolamento social deu-se de forma bastante abrupta, e os eventos foram uma forma de promover certa proximidade entre toda a comunidade da educação musical. Os fóruns funcionaram como as janelas que muitos músicos utilizaram àquela época para aproximar-se dos vizinhos.

O primeiro abordou o tema "Ações e reações para enfrentar as crises a partir de movimentos coletivos da educação musical brasileira" e contou com os professores Dr. Luis Ricardo Silva Queiroz (UFPB) e Dr. Marcus Vinícius Medeiros Pereira (UFJF/ABEM) como debatedores, tendo sido mediado pelo professor Dr. Mário André Wanderley de Oliveira (UFRN/ABEM). Deste fórum, a partir da participação da comunidade no chat, decidiu-se pelo tema do próximo: "Possibilidades online de Ensino/Aprendizagem Musical", que trouxe o Grupo TEDUM - Tecnologias e Educação Musical (Profa. Dra. Juciane Araldi Beltrame - coordenadora do grupo, e Prof. Me. Magnaldo Araújo e Prof. Me. Matheus Barros) para apresentar alguns recursos e estratégias para o trabalho on-line. A terceira edição contou com as professoras Dra. Renata Pereira (Centro Suzuki São Paulo / Quarteto Quinta Essentia) e Dra. Carina Joly (UFSJ), e abordou as "Aulas de instrumento online: compartilhando boas práticas".

Esses fóruns de temas emergentes, como comentado anteriormente, tiveram como objetivo, além de promover uma aproximação com a comunidade e possibilitar o debate sobre questões que passaram a povoar as vidas pessoais e profissionais de todos/as, compor testes preliminares para a realização de eventos on-line - característica que marcaria os eventos acadêmicos não só da ABEM no ano de 2020. Os fóruns de temas emergentes tiveram ampla participação, com seu alcance ampliado sobremaneira por ter suas mesas geradoras do debate transmitidas no canal do YouTube da Associação.

Dessa forma, diante do caráter persistente das medidas de distanciamento e isolamento social, os encontros dos fóruns permanentes de Pesquisa em Educação Musical e de Formação de Professores de Música foram realizados nesse mesmo formato, com transmissão pelo canal do YouTube da ABEM, tendo seus debates acontecido em três quintas-feiras consecutivas. 
O formato on-line permitiu não somente a ampliação do alcance do evento, inclusive pelo fato dos encontros permanecerem gravados e disponíveis no YouTube (há vídeos com duas mil visualizações), mas a participação de convidados internacionais, como a professora portuguesa Dra. Maria do Céu Roldão. As discussões, antes bastante ligadas às características dos locais que recebiam os encontros dos fóruns, tornaram-se mais amplas, e o chat ao vivo, enquanto os/as expositores/as apresentam suas contribuições, permitiu um debate entre a audiência.

Todo esse caminho contribuiu para que a diretoria, especialmente os/as coordenadores/as regionais da ABEM, iniciasse o planejamento dos eventos regionais que seriam realizados em diferentes localidades do país.

\section{Encontros Regionais Unificados da ABEM: uma experiência inovadora}

Com a pandemia ainda não controlada no Brasil, a realização dos cinco encontros regionais da $\mathrm{ABEM}$ precisaram ser realizados integralmente em ambiente virtual. Como as mesas-redondas seriam transmitidas pelo YouTube para todos o país, propusemos a realização dos encontros regionais de forma unificada: duas semanas de programação intensa envolvendo as cinco regiões do país. E, para preservar o caráter regional dos encontros e de seus debates, cada dia da primeira semana seria dedicado a uma das regiões, com mesas promovendo o debate de questões ligadas aos seus respectivos estados, sem deixar de permitir também o debate mais amplo e o diálogo com os participantes de todo o Brasil.

Como já havíamos realizado mesas-redondas durante os três fóruns $100 \%$ on-line em 2020, nossos maiores desafios no planejamento e realização dos Encontros Regionais Unificados foram atinentes às atividades que ainda não havíamos concretizado em formato exclusivamente on-line: 1) minicursos; 2) apresentações musicais; e, principalmente, 3) sessões destinadas aos/às autores/as das comunicações, pôsteres e simpósios.

Para os minicursos, foram estabelecidos três formatos não mutuamente excludentes, com vistas a contemplar diferentes formas de interação e possíveis limitações de recursos dos/as ministrantes e participantes: 1) PodCast, destinado a 
propostas expositivas, compatíveis com exposição exclusivamente oral e interações assíncronas; 2) Vídeo-Aula, destinado a propostas expositivas, com uso de recursos audiovisuais diversos e interações assíncronas; e 3) Meet, destinado a propostas mais dialogadas, com uso de recursos audiovisuais diversos e interações síncronas. Haja vista que a maioria dos/as ministrantes com propostas aprovadas já estava familiarizada com os formatos que escolheram, as atividades dos cursos transcorreram sem grandes imprevistos durante o evento.

Haja vista que seria complexo realizar ao vivo apresentações musicais em grupo durante o evento on-line, sugerimos que os/as coordenadores/as regionais da Associação designassem coordenadores/as artístico-culturais de suas respectivas regiões para, por sua vez, designarem curadores/as estaduais. As curadorias dos estados ficaram, assim, responsáveis por convidar grupos para produzirem vídeos editados de suas apresentações musicais. Os vídeos produzidos foram colocados como "vídeos de estreia" no canal do Youtube da ABEM, os quais foram assistidos como se fossem ao vivo, com comentários e interações nos chats — nos quais, em muitos casos, os/as músicos/as estavam presentes, interagindo com o público.

O maior desafio do evento possivelmente tenha sido organizar as reuniões com os/as autores/as de trabalhos (comunicações, pôsteres e simpósios) das cinco regiões. Em 2020, os cinco Comitês Científicos Regionais, composto por Presidentes/as e Coordenadores/as de GT, além dos/as pareceristas, atuaram de modo similar à forma como atuam no processo de avaliação de trabalhos para eventos presenciais da Associação. Os/as autores/as que tiveram seus textos aprovados, contudo, procederam, nos Encontros Regionais Unificados da ABEM, de modo diferente do habitual.

Com as apresentações prontas (gravadas em vídeo e com links disponibilizados aos/às inscritos/as no evento e a demais interessados), os/as autores/as puderam interagir com os/as interessados/as em seus trabalhos em três ambientes virtuais distintos e não mutuamente excludentes: 1) em posts na área de comentários dos vídeos no Youtube (interação assíncrona); 2) em grupos de WhatsApp (interação síncrona e/ou assíncrona); e 3) nas Sessões de Debate-SD (interações síncronas), as quais aconteceram, das 19h às 22h (horário de Brasília), nos dias 16, 17 e 18 de novembro, em salas virtuais do Google Meet. 
Diante de um cenário de desigualdade e, comumente, de precariedade no acesso à internet, a emissão de certificados aos/às autores/as dos trabalhos foi condicionada, em 2020, somente à disponibilização da gravação em vídeo da apresentação dos trabalhos (simpósios, comunicações ou pôsteres). Isso porque a obrigatoriedade da apresentação síncrona tornaria dificultosa - ou mesmo inviável - a participação de autores/as sem acesso à internet com qualidade necessária para interações síncronas. Sendo assim, embora estimulada, a presença dos/as autores/as nas Sessões de Debate (SD) não foi obrigatória.

Para a constituição das SD, os trabalhos aprovados nas cinco regiões foram agrupados por temáticas. Os agrupamentos gerados não corresponderam, necessariamente, aos Grupos de Trabalho (GTs) nos quais os textos foram submetidos e avaliados e nem às suas regiões. O objetivo desse procedimento foi estimular, nas sessões, o debate entre autores/as com interesses em comum - haja vista que, de outro modo, poderiam ficar em salas diferentes. As SD tiveram, como mediadores/as e provocadores/as, integrantes dos Comitês Científicos das cinco regiões. Cada sessão contou com um/a monitor/a que era também administrador/a do Grupo do WhatsApp e da Sala do Google Meet correspondentes à SD. Estimulamos todos/as os/as interessados/as a assistir aos vídeos das SDs de que participariam, para que pudessem contribuir e receber contribuições, fomentando assim o debate.

A articulação entre pesquisadores/as, professores/as e estudantes de música, possibilitou que, mesmo em contexto tão adverso, a circulação de trabalhos da área ocorresse de forma aberta, acessível, ainda que dentro de um formato novo para os eventos acadêmicos-científicos da Associação. Cabe frisar que as SD tiveram, no evento, uma adesão significativa de autores/as, ainda que sua presença fosse facultativa nas salas. O formato em que foram realizadas as apresentações e os debates possibilitaram, conforme relatos de diversos/as mediadores/as e autores/as, trocas mais produtivas do que aquelas observadas em edições presenciais de eventos da ABEM. Configuraram-se, em sua perspectiva, portanto, como sessões de debate de fato, mais do que sessões de comunicação que priorizam, em sua maior parte, a exposição dos trabalhos. Tal situação nos permitiu vislumbrar caminhos possíveis para a redefinição e reconfiguração dos GTs da Associação. 
Ainda dentro da programação dos Encontros Regionais Unificados, foi realizado o Fórum de Coordenadores/as dos Cursos de Licenciatura em Música. Quando realizados nos eventos presenciais, havia uma baixa adesão a esses fóruns, visto que muitos/as coordenadores/as não participavam dos encontros, solicitando que professores/as presentes nos eventos representassem seus cursos nas discussões. Nessa perspectiva, a realização de reuniões virtuais permitiu uma ampla participação de coordenadores/as, o que dinamizou e enriqueceu o debate.

Cabe mencionar, que, previamente, coordenadores/as de todo o Brasil responderam a um formulário on-line, contribuindo com dados que serão utilizados pela Associação em suas ações, e que foram discutidos com foco em cada região. Foram discutidas, ainda, temáticas relacionadas à Resolução CNE/CP n. 2, de 20 de dezembro de 2019, que aprovou a Base Nacional Comum para a formação inicial de professores e as alternativas de cada curso frente à necessidade de um ensino remoto emergencial. Desses fóruns de coordenadores/as de curso, um dos encaminhamentos para o futuro é uma maior constância desses encontros, com temáticas pontuais que permitam um maior aprofundamento nas discussões.

Foram comuns depoimentos durante e após os Encontros Regionais Unificados da ABEM que destacaram o seu caráter histórico, que marca um novo formato dos nossos congressos: um caminho sem volta. Nossa relação com a tecnologia, e a forma como esta tem mediado nossas relações, ganhou nova dimensão nesses tempos de pandemia. Fomos impulsionados/as em um caminho que já se mostrava no horizonte, mas ao qual, muitas vezes, apresentávamos forte resistência. A tecnologia, não deverá substituir nossos encontros presenciais, mas certamente estará presente ampliando o alcance das discussões, intensificando, ao mesmo tempo, o poder coletivo que a associação representa.

\section{Notas finais}

É no "instinto comunal”, proposto por Gibson (1982), que a ABEM tem procurado despertar e fortalecer continuamente a área da Educação Musical no Brasil. Um instinto que nunca foi tão urgente e necessário. $\mathrm{O}$ isolamento/distanciamento social que nos foi 
imposto exigiu e permitiu que fizéssemos jus às "significações genéricas" do termo "associação", que

remetem às ideias de "aliança", "união", "reunião", "colaboração", "união de esforços de várias pessoas para prosseguir um fim comum". $\mathrm{O}$ verbo associar-se, por sua vez, admite também como significado a ideia de "tomar parte", "participar", "relacionar-se com", "combinar-se". [...] De todos os pontos de vista, as associações traduzem um ímpeto pela ligação e pela partilha - aquilo que comumente se designa por networking (OLIVEIRA, 2017 , p. 234, grifo no original).

Se antes, esse entendimento de associação já era importante, durante a pandemia da COVID-19 tornou-se fundamental. Entre todas as ações promovidas pela ABEM, seus encontros vêm operacionalizando essa partilha, a criação de laços, a sensação de pertença a um coletivo. E esses eventos foram a escolha da associação para fazer com que a área pudesse sentir-se em conjunto, e pensasse em conjunto formas de superar toda essa crise.

Em tempos críticos como o que ora atravessamos, é fundamental despertar em todos o "sentido de militância e de envolvimento político", para que as ações tenham maior visibilidade e maior impacto. Somente assim nos tornaremos uma comunidade, que supera o desejo de estar conectado ou em rede, mas que age como um grande conjunto que é maior do que a soma simples de todos/as. É com o desejo de fomentar esse ideal de comunidade, de incentivar cada vez mais um maior engajamento nas lutas em prol da área, que a ABEM vem procurando ampliar o acesso e a participação nos debates e ações que promove.

Certamente a pandemia nos permitiu uma série de reflexões e autoavaliações, além de terem impulsionado mudanças que já se faziam urgentes. As ações e reações da ABEM marcam não somente adaptações necessárias, como disparam reinvenções oportunas na criação de um outro futuro. Futuro esse que, desejamos, continue a história que a associação vem construindo nos últimos 30 anos, consolidando-se, cada vez mais, como uma comunidade coesa e ativa na luta por uma educação musical de qualidade para todos os brasileiros e brasileiras. 


\section{Referências}

BRASIL. Ministério da Saúde. Painel coronavírus. Brasília: Ministério de Saúde, 2020. Disponível em: <https://covid.saude.gov.br>. Acesso em: 24 nov. 2020.

BRASIL. Lei $n$. 14.017, de 29 de junho de 2020. Dispõe sobre ações emergenciais destinadas ao setor cultural a serem adotadas durante o estado de calamidade pública reconhecido pelo Decreto Legislativo n. 6, de 20 de março de 2020. Diário oficial da União: seção 1, Brasília, DF, n. 123, p. 1, 30 jun. 2020. Disponível em: https:/www.in.gov.br/en/web/dou/-/lei-n-14.017-de-29-dejunho-de-2020-264166628. Acesso em: 24 nov. 2020.

CAPPRA, Ricardo. Na primeira pandemia acompanhada em tempo real, analista de dados mostra a importância da cultura analítica. ECOA - Por um mundo melhor, 2020. Disponível em: $<\mathrm{https}$ ://www.uol.com.br/ecoa/reportagens-especiais/o-mundo-pos-covid-19-5---tecnologia-eanalise-de-dados-por-ricardo-cappra/\#page1>. Acesso em: 17 nov. 2020.

CEE-FIOCRUZ: 'Covid-19 não é pandemia, mas sindemia': o que essa perspectiva científica muda no tratamento. Centro de Estudos Estratégicas da Fiocruz. Disponível em $<$ https://cee.fiocruz.br/?q=node/1264>. Acesso em: 23 nov. 2020.

COMITÊ GESTOR DA INTERNET NO BRASIL. Pesquisa sobre o uso de tecnologias de informação e comunicação nos domicílios brasileiros - TIC Domicílios 2017. <Disponível em: $<$ https://data.cetic.br/cetic/explore>. Acesso em: 23 nov. 2020.

FIORILLO, Marília. Negacionismo científico no governo é inimigo do combate à pandemia. JORNAL DA USP, 2020. Disponível em: <https://jornal.usp.br/radio-usp/negacionismocientifico-no-governo-e-inimigo-do-combate-a-pandemia/>. Acesso em: 23 nov. 2020.

FURCERI, Davide; LOUNGANI, Prakac; OSTRY, Jonathan D. Como as pandemias deixam os pobres mais pobres. International Monetary Fund, 2020. Disponível em: $<$ https://www.imf.org/pt/News/Articles/2020/05/11/blog051120-how-pandemics-leave-thepoor-even-farther-behind?sc_mode=1>. Acesso em: 23 nov. 2020.

FCC. Educação escolar em tempos de pandemia. Fundação Carlos Chagas. Informe no 1, 2020. Disponível em: <https://www.fcc.org.br/fcc/educacao-pesquisa/educacao-escolar-em-temposde-pandemia-informe-n-

1 ?utm_source=mailpoet\&utm_medium=email\&utm_campaign=Informe-1-primeirosresultados\&fbclid=IwAR1ISJU-CQOATZySWp8h76LvS1V-

s2q_s_2V1Rz29m53Neod6LHpUErefpE>. Acesso em: 23 nov. 2020.

GIBSON, Sarah. S. Scientific societies and exchange: a facet of the history of scientific communication. The Journal of Library History, v. 17, n. 2, p. 144-163. 1982.

GUSSO, Hélder Lima; ARCHER, Aline Battisti, LUIZ, Fernanda Bordignon; SAHÃO, Fernanda Torres; LUCA, Gabriel Gomes de, HENKLAIN, Marcelo Henrique Oliveira; PANOSSO, Mariana Gomide; KIENEN, Nádia; BELTRAMELLO, Otávio; GOLNÇALVEZ, Valquiria Maria. ENSINO SUPERIOR EM TEMPOS DE PANDEMIA: DIRETRIZES À GESTÃO UNIVERSITÁRIA. Educ. Soc., Campinas, v. 41,2020. Disponível em: $<$ http://www.scielo.br/scielo.php?script=sci_arttext\&pid=S0101$73302020000100802 \& \operatorname{lng}=\mathrm{en} \& n \mathrm{~mm}=\mathrm{iso}>$. Acesso em: 24 Nov. 2020. 
HORTON, Richard. Offline: COVID-19 is not a pandemic. The Lancet, v. 396, 2020. Editorial. Disponível em: <https://www.thelancet.com/journals/lancet/article/PIIS0140-6736(20)320006/fulltext>. Acesso em: 23 nov. 2020.

IBGE. IBGE estima população do país em 211,8 milhões de habitantes, Agência de Notícias $I B G E$, 2020. Disponível em: <https://agenciadenoticias.ibge.gov.br/agencia-noticias/2012agencia-de-noticias/noticias/28676-ibge-estima-populacao-do-pais-em-211-8-milhoes-dehabitantes>. Acesso em: 23 nov. 2020.

ROSA, Mariana Guidetti; NOCCIOLI, Carlos Alexandre Molina. Achatar a curva, INFORMA SUS-UFSCAR, 2020. Disponível em <https://www.informasus.ufscar.br/achatar-a-curva/ 2020>. Acesso em: 23 nov. 2020.

JESUS, Patrícia Britto Ribeiro de; BONFIM, Camila Santos; COSTA, Elisabete Mariano da; RIBEIRO, Jacqueline Castro Veras; CAMPOS, Laís Ferreira; FRAGA, Taísa Gabilan; ALMEIDA, Thaís Fernanda de; SANTOS, Thatiane Côrrea dos; SILVA, Rayanne Prevost da. Planning and participation of online scientific event as an educational and interactive resource in EaD teaching: an experience report. Research, Society and Development, [S. 1.], v. 9, n. 9, 2020. Disponível em: $<$ https://rsdjournal.org/index.php/rsd/article/view/7163>. Acesso em: 17 nov. 2020.

JOHNS HOPKINS UNIVERSITY. COVID-19 Map. Johns Hopkins Coronavirus Resource Center. 2020. Disponível em: <https://coronavirus.jhu.edu/map.html>. Acesso em: 24 nov. 2020.

OPAS/OMS Brasil. Entenda a infodemia e a desinformação na luta contra a COVID-19, OPAS/OMS $\quad$ Brasil, $2020 . \quad$ Disponível em $<$ https://iris.paho.org/bitstream/handle/10665.2/52054/Factsheet-

Infodemic_por.pdf?sequence $=14>$. Acesso em: 23 nov. 2020 .

OLIVEIRA, Madalena. Associações científicas: da ideia de rede ao ideal de comunidade. In: MARTINS, M. L. (Org.). A internacionalização das comunidades lusófonas e ibero-americanas de Ciências Sociais e Humanas - o caso das Ciências da Comunicação. Vila Nova de Famalicão: Húmus, 2017. 231-246. Disponível em $<$ http://www.lasics.uminho.pt/ojs/index.php/cecs_ebooks/article/view/2722>. Acesso em: 17 nov. 2020.

PEREIRA, João Thomaz. Educação e Sociedade da Informação. In: COSCARELLI, Carla Viana; RIBEIRO, Ana Elisa. (Orgs). Letramento digital: aspectos sociais e possibilidades pedagógicas. 3 ed. Belo Horizonte: Ceale; Autêntica, 2011. p. 59-83.

PEREIRA, Daniervelin Renata Marques; CANALLI, Hugo Leonardo. Evento online: a experiência do EVIDOSOL/CILTEC-ONLINE. In: Encontro Virtual de Documentação em Software Livre, IX, e Congresso Internacional de Linguagem e Tecnologia Online, VI, 2019, Belo Horizonte. Anais... Belo Horizonte: UFMG, 2019. p. 1 - 5.

RODRIGUES, Meghie. O progresso da ciência é língua universal de associações pelo mundo. Cienc. Cult., São Paulo, v. 70, n. 3, p. 22-24, Julho 2018. Disponível em: $<\mathrm{http}$ ://cienciaecultura.bvs.br/scielo.php?script=sci_arttext\&pid=S0009-

$67252018000300007 \& \operatorname{lng}=\mathrm{en} \& \mathrm{nrm}=\mathrm{iso}>$. Acessado em 14 Nov. 2020.

SALLES, João Carlos. Com aulas remotas, pandemia escancara desigualdade no acesso à educação de qualidade. [Entrevista concedida a Caroline OLiveira] Nome do Entrevistador. Brasil de Fato, 2020. Disponível em: < https://www.brasildefato.com.br/2020/06/04/com-aulas- 
remotas-pandemia-escancara-desigualdade-no-acesso-a-educacao-de-qualidade $>$. Acesso em: 22 nov. 2020.

SANTOS, Ricardo Ventura; PONTES, Ana Lúcia; COIMBRA JR., Carlos. Um "fato social total": COVID-19 e povos indígenas no Brasil. Cad. Saúde Pública, Rio de Janeiro, v. 36, n. 10, e00268220, Set. 2020. Disponível em: <http://cadernos.ensp.fiocruz.br/csp/artigo/1194/um-fatosocial-total-covid-19-e-povos-indigenas-no-brasil> Acesso em: 17 de novembro de 2020.

SIEGELMAN, S. S. (1998). The genesis of modern science: contributions of scientific societies and scientific journals. Radiology, v. 208, n. 1, p. 9-16.

UNESCO. COVID-19 Educational Disruption and Response. Paris: Unesco, 30 July 2020a. Disponível em: <http://www.iiep.unesco.org/en/covid-19-educational-disruption-and-response13363>. Acesso em: 22 maio 2020.

WERNECK, Cláudia. COVID-19 transformou a vida em um eterno webnar. ECOA - Por um mundo melhor, 2020. Disponível em: $<$ https://www.uol.com.br/ecoa/colunas/opiniao/2020/05/04/covid-19-transformou-a-vida-emum-eterno-webinar.htm>. Acesso em: 17 nov. 2020.

WITTER, Geraldina. Importância das sociedades/associações científicas: desenvolvimento da ciência e formação do profissional - pesquisador. Bol. psicol, São Paulo, v. 57, n. 126, p. 1-14, jun. 2007. Disponível em $<$ http://pepsic.bvsalud.org/scielo.php?script=sci_arttext\&pid=S000659432007000100002\&lng=pt\&nrm=iso>. Acesso em 17 nov. 2020.

WHO. Coronavirus disease (COVID-19) pandemic. Geneva: World Health Organization; 2020. Disponível em: <https://www.who.int/emergencies/diseases/novel-coronavirus-2019>. Acesso em: 23 nov. 2020. 
